ON

\title{
PAINFUL AFFECTIONS OF THE SIDE
}

\author{
FROM \\ TUMID SPLEEN. \\ BY ROBERT BREE, M.D. F.R.S. \\ Read January 1, 1811.
}

AMONGST the painful affections of the side that may be attributed to internal causes, the disorders of the spleen are distinguished with difficulty in their early stage.

The histories of morbid spleen which have been given by anatomists, do not furnish a satisfactor account of the early signs of the disease. The symptoms which recently preceded death, are often minutely detailed; but as these are necessarily connected with the states of other viscera which had suffered inflammation, the case is deprived of its distinct character, and the description shews the result of complicated disorders, but explains 
little of their progress, and still less of the beginning of a simple and limited complaint.

Of the state of the spleen itself, they report certain appearances which must have proceeded from disease, and not from original defect of structure.

The spleen has been wasted to the smallest size; the capsule only containing a little of its reticular or vascular substance, and possessing its peritoneal covering.

A second state is the excessive enlargement of the spleen. The natural weight of this organ may vary from 9 ounces to 14 ounces; but after chronic diseases of the viscera, and intermittent fevers, it has weighed from one pound to 20 , and even 30 pounds.

A third state is that of its structure being destroyed, and its substance corrupted or broken down into a sanious mass, which has often distended, and sometimes ruptured the coats. This condition has been the sequel of long protracted disease, or the effect of fevers of a rapid and peculiar character.

Fourthly, a great portion of the substance of the spleen has been found in a cartilaginous state; and its peritoneal coat has been occasionally ossified. 
Systems of medicine do not afford us more satisfaction by their descriptions of Splenitis : Cullen says (ccccxxv) that it may be readily known by his definition in the Nosology: he refers also to his doctrine on the inflammation of the other abdominal viscera for the practice which it requires, as well as for information respecting its three modes of termination, by " resolution, suppuration, or gangrene."

His account of Splenitis agrees with that of writers in general, but it corresponds so little with the facts which actually appear in the early stages of the disease, and the practice is so insufficient or inapplicable at this period, that it is surprising the defect should hitherto have escaped observation.

Splenitis, or more properly speaking, "s the tumid and painful Spleen," is not at its commencement a febrile disease; and yet this affection is so sensibly felt, that the character by which chronic Hepatitis is distinguished from acute, cannot be applied to it. Whilst inflammatory or febrile ac. tion is absent, the disease cannot terminate by "suppuration or gangrene." Nor can it, for the same reason, end by "resolution," if this term be taken in its ordinary meaning.

It will appear that the turgid condition of this viscus may continue for many months, during 
which time the pain may be acute, and the swelling may be perceptible under the spurious ribs, and no fever may attend the complaint.

An increase of pulse takes place, as recovery from the actual disease proceeds, so that it not only might exist without fever, but a moderate degree of fever may be an indication of the return of health to the organ.

It must be unnecessary to speak here of the structure of the spleen, after the account which has been given of this viscus by Cuvier, and confirmed by the recent investigation of $\mathrm{Mr}$. Hоме.

The parenchyma of this viscus, however little it may be disposed to inflammation, is susceptible of injury from the distension of its numerous vessels, which may be so great as' to overcome their power of contraction, at the same time that the ligamentous fibres may be weakened in an equal degree, or wholly lose their elasticity. Inflammation may be expected to supervene on this condition at some period; but I believe this never takes place, except on the accession of injury to the peritoneal coat, either from the internal distension having been of long standing, or from external violence.

Having had favourable opportunities of consider- 
ing abdominal diseases complicated with asthmatic affections, $I$ have been led to pursue a treatment which I have thought more appropriate to the nature of splenic disorders, than what I had been directed to by books, or had observed in general practice.

I had noticed, in a protracted case of Dyspnœea, with pain of the left side, the manifest relief that was obtained from a free discharge of hæmorrhoids, and I endeavoured to imitate this process of nature. The patient was a young man of 22 years of age. He had suffered attacks of Tertian Fever two years before, and had been in feeble health, with constant uneasiness of the left side, during the last year. The ague had left him when he changed his residence a year and a half preceding my attendance; but the pain of his side had resisted all the means that had been applied for his relief. At length the piles bled considerably for the first time, and he was restored to his former ease for three months. On the approach of winter, the disease returned and gradually became as oppressive as before. He was unable to rest on his right side. There was no external sign of enlargement on the left side ; but he had a sense of weight and fulness, with severe pain under the short ribs, extending to the lowest rib on that side. There was no fever, and the state of the belly and urine was natural. I proceeded to treat the case with aloetic aperients 
united with Assafetida and Sulphate of Potash. In a few weeks the piles returned and carried off the complaint. As I had considered this pain of the side as an affection of the spleen, I placed the result of the case amongst the facts that influenced my opinion on similar disorders, which afterwards came under my care. Many of these were cases of female patients, in whom Dyspnœa and pain in the region of the spleen, were wholly removed or greatly relieved by the flow of the menses.

I was directed by this experience, casually acquired, to the practice which $I$ have since pursued in diseases of the spleen.

I beg to submit to the consideration of the Society the following case, as explanatory of the remote cause of turgid and painful Spleen, and of the manner of treating this affection with success.

\section{CASE.}

M.A. October 26, 1809.

This young lady is 17 years old, of a fair complexion, and of much vivacity and intelligence of mind. She has pain of the left side, which be- 
gan a month ago, and has gradually increased to the present time. She is unable to lie on the right side, as this posture aggravates the pain of her left side. She has no expectoration, but occasionally a very trifling short cough.-Pulse is 62 , and soft. Upon examining the side, no difference is perceived by the eye or hand, but she feels pain under the short ribs upon pressure, and the pain descends lower than the ribs. She is also sensible of bulk and weight under these ribs, which extend from the margin of the eighth rib to the lowest rib, and backwards to the spine. She was at school when this complaint was first felt in a slight manner. She had a puke and dose of Calomel given to her without relief; but there was no particular examination of the part at this time. The pain afterwards became gradually connected with giddiness of the head, and difficulty of breathing, particularly when the body was put in motion. In this state she was brought to her friends in town. Two months before this date, and one month before she complained of local pain, she had been bathing in the sea, with some young friends of her family; and she plunged herself 62 times into the water, in a playful humour and in opposition to the advice of the elder part of the company. Though she does not allow that she received immediate injury from this act, it had been considered by her friends as injurious, and it was always referred to by them as the cause of her complaint. 
The symptoms I have enumerated, appeared to indicate congestion in the spleen; nor could I account for the slowness of the pulse, accompanied as it was with fixed and acute pain in the region of the spleen, and difficulty of breathing, by any other probable cause. I prescribed only saline draughts with opium every six hours, and an aperient every morning, at this visit.

October 31st.-I had seen Miss A. several times. I found little variation in the symptoms. A small quantity of wine had aggravated her complaints of vertigo and local pain. The pulse was never more frequent than 62 , and generally at 60 . There was no heat of the skin, and no sickness attended her vertigo. The tongue was clean, and the discharges of stool and urine natural. There was no cough. But her nights were very much disturbed by the difficulty of lying easy in any posture, and particularly on her sides, the pain of the left side being insupportable when she turned to her right side. The plan of medicine had not been varied; but she had been bled largely without relief. The blood was not inflamed, but so loose in its texture, as to shew the operation to have been useless, if not improper. Blisters had been applied with as little advantage. She was now directed to take a pill of Calomel and Opium every six hours, with her saline draught, and the purging draught every morning made more active by Tincture of Jalap and Alöes. 
To abate pain, Pulv. Ipecac. compos. was directed to be taken in sufficient doses at bed-time.

She proceeded on this plan for several days, during which time her pulse did not rise higher than 64, and generally was found at 60. The urine was increased in quantity, and the skin was more disposed to perspire. She had two loose stools every day. She yet experienced no ease in any posture in her bed, excepting on the back.

Nov. 17.-In the first week of November, Miss A. appeared to have some relief; but none of her complaints were removed: and in addition to them she had experienced palpitation of the heart, which also interrupted her repose. She complained in general of more languor than she had been used to feel before she was bled. She had had five grains of Extract of Conium twice a day in her pills for the last week : and she took three days since an active vomit, which occasioned the discharge of a large mass of mucus, so considerable as to surprise the observers. There was no bile thrown off, nor any thing that had a particular taste. No benefit or change of feeling resulted from this operation, excepting that she found herself lighter at the præcordia. The vertigo at this time was so distressing, that she could not walk across the room without assistance to prevent her from falling.

I now determined to make trial of a plan, whicil 
might strengthen and excite the system. I prescribed 15 grains of myrrh with carbonated ammonia and camphor mixture to be taken every six hours. The former medicines were to be discontinued, excepting such proportions of Opium and Extract of Conium, as might be necessary to abate pain.

Nov. 24.-She perceived some relief of her languor, but no mitigation of the other symptoms. Three grains of Sulphate of Iron were now prescribed in a draught, with myrrh and camphor, to be taken every six hours; and the bowels were to be kept open by the usual means. She was also advised to try the effect of gentle exercise on horseback.

Dec. 10.-Miss A. had not yet rode on horseback. The tonic plan had been frequently varied. She had taken Bitters-Decoct. Cinchonæ-Infus. Cascarillæ with Rhubarb-Extract of Hop and Sulphate of Zinc, besides the forms before reported. The pulse had remained during this course at the average of 60 , and had therefore been something less frequent than $I$ had generally observed it to be, during the course of saline aperients with Calomel. She now made one trial of horse exercise at a gentle walk, but was obliged to desist in half an hour, from the increase of pain of the side, which gradually became insupportable. After this she considered her complaint worse, which 
she attributed to the riding; but it was evident that the tonic plan had a full share in producing the aggravation of her complaint. I examined her side, where she assured me she felt much increase of bulk, and I perceived a protrusion of substance from within to the margin of the false ribs. This swelling was so manifest on several examinations, that my attention was recalled to the treatment which $I$ had applied in other cases of a similar nature, and which had been partly pursued in this with more success than the last which I had directed.

Dec. 15.-I advised her to remain constantly in her chamber, that she might pursue without deviation a course of medicines, by which the secretions were to be much increased, and determined chiefly to the bowels and kidneys, whilst the body was in a state of rest. She was willing to acquiesce in all my directions, and I resolved to act upon this principle for a considerable length of time. A saline draught was ordered to be given every six hours, with one grain of Aloes and five grains of Extract of Conium.

Dec. 26.-Having pursued this plan during ten days without variation, excepting in the degree of the strength of the purgative, the symptoms were reduced to the state which prevailed in the last month. The saline aloetic draughts had produced several motions daily without lowness. The me- 
dicines were continued with 15 grains of nitre in each draught.

Jan. 9, 1810.-At the beginning of this month, Miss A. was sensible of considerable relief from her complaint; but she was still unable to lie upon the right side. The urine was copious, and perspiration free every night. She had five or six motions daily without any sense of languor; and this state of the bowels seemed to conduce most materially to her improvement. She was recommended to take two grains of antimonial powder, and two grains of Aloes three times a day, with gr. iv. of Extract of Conium. A saline draught with nitre and camphorated Tinct. of Opium was to be taken every night at bed-time.

Feb. 1.-Upon an examination and pressure of the side at the end of January, she was found to be much less sensible of uneasiness, and there was no appearance of swelling. But she still suffered too much to persist in any attempt at lying on the right side. Her Dyspnœa was less, she could move without giddiness, and she was much improved in flesh and colour, notwithstanding her close confinement. The pulse had risen to the average of 75. She was directed to continue the medicines with the addition of four grains of Extractum $\mathrm{Pa}$ paveris at bed-time.

Feb. 5. - The bowels were more torpid than be- 
fore she took the Extr. Papav. which, as it had not produced more rest in the night, was discontinued. A mixture of Infusion of Senna with neutral salts was directed to be taken every morning, and the aloetic antimonial pills to be continued.

In the middle of February she was so far improved, as to propose to leave her chamber. She had insensibly come to lie on the right side. And her complaints were so little felt, as to be spoken of with indifference. The pulse was 80 .

March 1.-Miss A. had been a sufferer with her disease above five months; and she had lived in her chamber nearly three months. The catamenia had been regular, and always relieved her complaints. She now considered herself well, as her nights were good, and she very seldom felt pain in her side, difficulty of breathing, or giddiness, and she could use exercise without inconvenience, She was free from all her complaints in the middle of the month; and at the end of March she performed a long journey without suffering any relapse. At the present time she is perfectly well, and much fatter than she was before her illness.

It would be intruding upon the time of the Society, if I were to go into a comparison of this case with others, in which congestion and inflam. mation of the spleen had been proved by examination after death. Its identity has been confirmed 
to me by the observation of many cases that had been previously under my care. And I believe that the more advanced stages of Splenitis, in which inflammation has affected the membranous coverings and connected viscera, may be often followed up to this simple state of disease, as the root from which such complicated disorder had grown.

This and other instances of similar affections, have suggested to me some inferences, which I now offer with deference to the consideration of the Society.

This disease appeared to be the direct effect of a repressed circulation from the application of cold to the surface of the body, and every consideration of the nature of such a cause leads to the conclusion, that congestion had taken place in the Spleen.

Whatever degree of pain was suffered, it did not increase the frequency of the pulse, which remained at a slower rate than was natural in the state of health. consider this state of the pulse as diagnostic of the turgid state of the Spleen, when it is accompanied by the symptoms of great pain, and of inability of lying on the contrary side; in which position, the heavy and enlarged Spleen acts as a dead weight, drawing the diaphragm, and distressing the adjoining parts. The 
absence of fever may be explained by the nature of the structure of this organ. It must have great capacity in its arteries when they are dilated to receive blood, that is impelled into them: and it suffers distension for the safety of the system, pyr- . exia being prevented by the actual turgescence of all its vessels. It is more than probable that there may be pains of the side from turgescence of the Spleen, of so obtuse or mild a nature, as to be supported without much complaint. Relief from these pains may be obtained by determining the blood to the lower belly and pelvis : and they are to be partially removed from women by the increase of the catamenia, and from men by the bleeding of the hæmorrhoidal vessels. When there is much Dyspnœa, without fever, attending a heavy uneasiness in the left side, the Spleen may be considered as the suffering part, even if there be no external tumor. This conclusion will be stronger, if there be giddiness of the head and distress from lying on the right side. We may presume, that though the internal structure of the Spleen is loaded with blood, the capsule and the peritoneal coat are not yet distended, or not in a considerable degree.

From this inferior degree of affection, a more formidable complaint must grow, if it be neglected, or treated erroneously.

The integuments are next distended, and the H 2 
pain increases in greater proportion than the distension. The diaphragm is spasmodically affected, and the uneasiness is carried under the sternum to the opposite side, whilst the Dyspnœa takes on the character of convulsive asthma. The vertigo upon motion of the body, increases with all other symptoms. There is no fever even yet, and therefore, notwithstanding such an extent of suffering, there is no inflammation.

I consider this collection of symptoms to make the first stage of splenitis, or turgid and painful spleen.

With respect to the treatment of this disease, the rules for its removal are few and limited. This will not appear extraordinary, if we attend to its structure and its œconomy, which seem to require a peculiar practice.

The blood must not be driven into it by stimulants during its state of debility : it must then be allow. ed to rest, that the energy of its vascular and ligamentous substance may have time to recruit. The œconomy of the spleen will, in every respect, make this process slow; but during its passive state, the hæmorrhoidal arteries may be excited to receive an unusual portion of the circulating mass, and to discharge it. The excretories of the kidneys, and the exhalants of the intestines, and the hæmorrhoidal vessels may all produce relief to 
the spleen when their action is increased. I have not found issues, blisters, or any other external applications produce the slightest advantage.

Bleeding may be supposed to be useful, as it lowers the impulse of the blood to the organ affected, giving its vessels time to exert themselves by rest. Yet this means has not answered well, possibly because it may lower the general tension without promoting that fulness of the vessels going downwards, which is necessary to recovery.

Bleeding by leeches, as well as blisters, must be necessary in the advanced stages, where the peritoneal coat is inflamed, and adhesions have taken place, but vee are not treating of this part of the progress of the splenic disease.

Mercury has appeared to be injurious, excepting as it may be directed to the purpose of purging the intestines and opening their exhalants.

Chalybeate tonics might be expected to be eminently serviceable in the passive state of the splenic vessels ; but in this expectation we are disappointed, unless they be given after these vessels and the ligamentous part of the spleen have recovered some degree of contractile power. If the circulation be hurried before this improvement has taken place, or if it be excited at any period of the complaint in an undue degree, the turgescence 
102 ON PAINFUL AFFECTIONS OF THE SIDE, \&c.

will be augmented in proportion to the action of the heart and arteries.

If there be any exception to this remark, it must apply in very depressed states of the habit, the consequence of long protracted illness.

Whenever the spleen is turgid, the blood should be diverted from finding its course to this organ; which is most likely to be effected by determining it to the other vessels of the abdomen and pelvis. In attempting to produce this necessary change, and in the intention of cure, aloës with antimonials and neutral salts have appeared to me to be the most successful instruments, when used twice in the day at least with great perseverance, and not as cathartics are generally prescribed, at intervals longer than twenty-four hours. 